\title{
Light-Scattering Patterns from Collagen Films in Relation to the Texture of a Random Assembly of Anisotropic Rods in Three Dimensions*
}

\author{
Masahiko Moritani, ${ }^{* *}$ Norio Hayashi, Akira Utsuo, ${ }^{* * *}$ \\ and Hiromichi KAWAI ${ }^{* * * *}$ \\ Department of Polymer Chemistry, Faculty of Engineering, \\ Kyoto University, Kyoto, Japan.
}

(Received September 2, 1970)

\begin{abstract}
Polarized light scattering from several types of collagen films cast from an acid soluble collagen and solubilized collagens by proteolitic enzyme (except callagenase) and from denatured films under various conditions, was observed under $H_{v}$ and $V_{v}$ polarization conditions.

The scattering patterns from the collagen films were different from those from spherulitic films of polyalphaolefins. The patterns were analyzed in terms of a three-dimentional random assembly model of anisotropic rods resulting in the following conclusions. The polar angle of orientation of scattering elements with respect to the rod axis ranged from 50 to $70^{\circ}$, depending on the type of collagen film. The value of $p$, which is defined by $\left(\alpha_{\perp}-\alpha_{s}\right) /\left(\alpha_{\|}-\alpha_{\perp}\right)$, changes from very positive in the air-dried state to less positive, zero, or even slightly negative in the swollen state in saline, also depending on the types of collagen film.

On the other hand, the characteristic $H_{v}$ patterns were diminished in intensity with denaturation while the $V v$ patterns-as well as the wide angle X-ray diffraction patternwere not changed to the same extent. This suggests that the light scattering from denatured films arises mainly from correlation in density fluctuations rather than that of orientation of local anisotropy; that is, it is suggested that denaturation causes disintegration of the crystalline superstructure rather than of the crystallites. These crystallites are too small in their correlation distance of the orientation fluctuation to give $H_{v}$ scattering at such small scattering angles as several degrees only.

KEY WORDS Polarized Light Scattering/Collagen Film/Denatured Film / Crystalline Texture / Anisotropic Rod / Random Assembly Model / Calculation / Swelling / Saline /
\end{abstract}

Light scattering from polymer systems in the solid state has been studied from two approaches.

* Part of the M.S. thesis of M. Moritani presented to the Department of Polymer Chemistry, Faculty of Engineering, Kyoto University, on March 10, 1970; presented to SPSJ 19th Annual Meeting, Tokyo, May 22, 1970.

** Present address: Reseach Laboratories, Niihama Factory, Sumitomo Chemical Co. Ltd., Niihama, Ehime, Japan.

*** Present address: Research Laboratory, Japan Leather Co. Ltd., Midori-cho, Senju, Kita-ku, Tokyo, Japan.

**** To whom any correspondence should be addressed.
One is the amplitude method, applicable to the systems having a rather definite superstructure of high symmetry, ${ }^{1}$ and the other is the correlation method for systems of low symmetry being much less definite in the geometry of their superstructures. ${ }^{2,3}$

Using the amplitude method, the polarized light-scattering patterns from poly- $\alpha$-olefins, such as polyethylene and polypropylene, were adequately explained in terms of three-dimensional (spherulitic) or two-dimensional (disc-like) crystalline textures in circular symmetries. ${ }^{4-6}$ In addition, the circular symmetry has been modified to some extent to asymmetric for structures like sheaf-like or truncated discs, 
in order to explain the light-scattering patterns from particular specimens having more or less disordered crystalline superstructures. ${ }^{7-9}$

On the other hand, the polarized light-scattering patterns from some polymers, such as polytetrafluoroethylene $\mathrm{e}^{10,11}$ and natural cellulose, ${ }^{12}$ have been found to be quite different from those from the poly- $\alpha$-olefins. These scattering patterns have been explained by also using the amplitude methods in terms of a crystalline texture of two dimensional random assembly of anisotropic rods, whose principal optical axis is either

Table I. Physical characterizations of test specimens and conditions under which they were cast into film specimens

\begin{tabular}{|c|c|c|c|c|c|c|}
\hline \multirow{2}{*}{$\begin{array}{l}\text { Speci- } \\
\text { men }\end{array}$} & \multirow{2}{*}{$\begin{array}{l}\text { Source of } \\
\text { collagen }\end{array}$} & \multirow{2}{*}{$\begin{array}{l}\text { Casting and } \\
\text { denaturation } \\
\text { conditions }\end{array}$} & \multirow{2}{*}{$\begin{array}{c}\text { Bire- } \\
\text { fringence }\end{array}$} & \multirow{2}{*}{$\begin{array}{c}\text { X-ray } \\
\text { diffraction } \\
\text { diagram }\end{array}$} & \multicolumn{2}{|c|}{ Turbidity } \\
\hline & & & & & Air-dried & $\begin{array}{l}\text { Swollen } \\
\text { in saline }\end{array}$ \\
\hline SC-I & $\begin{array}{l}\text { Acid soluble collagen } \\
\text { from fresh calf skin }\end{array}$ & $\begin{array}{l}\text { Cast into thin film } \\
\text { from about } 1 \% \text { solu- } \\
\text { tion in acidic aque- } \\
\text { ous solvent of } \mathrm{HCl} \\
(\mathrm{pH}, 2)\end{array}$ & $\begin{array}{l}\text { Slightly } \\
\text { positive }\end{array}$ & $\begin{array}{l}\text { Three fairly sharp } \\
\text { rings, with the } \\
\text { middle ring super- } \\
\text { imposed with a } \\
\text { diffuse halo }\end{array}$ & Transparent & $\begin{array}{l}\text { Turbid } \\
(65)^{\mathrm{a}}\end{array}$ \\
\hline $\begin{aligned} \text { RC-I } & \text { I } \\
& c \\
& s\end{aligned}$ & $\begin{array}{l}\text { Enzymatic solubilized } \\
\text { collagen from fresh } \\
\text { steer hide }\end{array}$ & Do. & none & Do. & Transparent & $\begin{array}{l}\text { Turbid } \\
(65)^{\mathrm{a}}\end{array}$ \\
\hline RC-II & Do. & Do. & none & Do. & Transparent & $\begin{array}{c}\text { Transparent } \\
(20)^{\mathrm{a}}\end{array}$ \\
\hline RC-III & Do. & Do. & none & Do. & Transparent & $\begin{array}{l}\text { Turbid } \\
(35)^{\mathrm{a}}\end{array}$ \\
\hline RC-IV & Do. & Do. & none & Do. & Transparent & $\begin{array}{c}\text { Transparent } \\
(5.5)^{\mathrm{a}}\end{array}$ \\
\hline $\begin{array}{rr}\text { MC-I } & 1 \\
c \\
\mathrm{~F} \\
\mathrm{r} \\
\mathrm{r}\end{array}$ & $\begin{array}{l}\text { Mixture of natural } \\
\text { collagen fibers with } \\
\text { RC-I at a fractional } \\
\text { ratio of } 70 / 30\end{array}$ & $\begin{array}{l}\text { Cast into thin film } \\
\text { from a suspension } \\
\text { of mechanically dis- } \\
\text { integrated natural } \\
\text { collagen fibers in } \\
\text { acidic aqueous solu- } \\
\text { tion of RC-I }\end{array}$ & none & Do. & Opaque & - \\
\hline MC-II & Same as RC-I & $\begin{array}{l}\text { Denatured by dip- } \\
\text { ping a precrosslinked } \\
\text { RC-I film, by means } \\
\text { of glutaraldehyde } \\
\text { treatment, in a } \\
\text { water-bath at } 85^{\circ} \mathrm{C} \\
\text { for } 10 \mathrm{~min}\end{array}$ & none & Do. & Transparent & - \\
\hline MC-III & Do. & $\begin{array}{l}\text { Denatured by dip- } \\
\text { ping a precrosslinked } \\
\text { RC-I film, by means } \\
\text { of ultraviolet ray } \\
\text { radiation in swollen } \\
\text { state, in a water- } \\
\text { bath at } 55^{\circ} \mathrm{C} \text { for } \\
10 \mathrm{~min}\end{array}$ & none & Do. & Transparent & - \\
\hline MC-IV & Do. & $\begin{array}{l}\text { Denatured in the } \\
\text { solution state at } \\
45^{\circ} \mathrm{C} \text { and cast into } \\
\text { thin film }\end{array}$ & none & Do. & Transparent & - \\
\hline
\end{tabular}

a The value drawn in brackets shows the optical absorption coefficient $\tau$ defined by $I=I_{0} \exp (-\tau I)$, where $I$ is the thickness of the film specimen in $\mathrm{cm}$. 
in parallel or perpendicular, ${ }^{13}$ or inclined at a given angle ${ }^{14}$ to the rod axis.

In this paper, the polarized light-scattering patterns from several types of collagen films, which appear similar to natural cellulose, will be discussed in terms of a three-dimensional random assembly of anisotropic rods of definite length but infinitesimally thin in their transverse direction. Optical anisotropy of the rod will be assumed so that the polarizability ellipsoids of the scattering elements are oriented side-byside within the rod, as illustrated in Figure 8, with a given polar angle $\omega_{0}$ to the rod axis.

The results obtained should be useful not only for extending the rod assembly model of light scattering from two-dimensional to three-dimensional systems, but also in presenting some models of superstructures of collagen systems of colloidal dimensions.

\section{TEST SPECIMENS AND EXPERIMENTAL PROCEDURES AND RESULTS}

Table I shows some physical characteristics of five types of collagen films cast from an acid soluble collagen and solubilized collagens by proteolitic enzymes except callagenase, which are designated as SC-I and RC-I through RC-IV, respectively, and four kinds of modified collagen films from the RC-I prepared by heat denaturation, designated as MC-I through MC-IV. Conditions for casting into thin films of about $0.1-\mathrm{mm}$ thickness are also given in this table, together with details of X-ray diffraction diagrams, turbidity, and birefringence.

The acid soluble collagen, SC-I, was extracted from fresh calf skin by using a method proposed by Doty and Nishihara, ${ }^{15}$ while the other solubilized collagens, RC-I through RC-IV, were prepared from fresh steer hide by means of enzymatic treatment using acid protease produced from aspergillus nieger. ${ }^{16}$ These collagens were disolved in an acidic aqueous solution of $\mathrm{HCl}(\mathrm{pH}, 2)$ to give a weight fraction of about $1 \%$, filtered by sintered glass filter (JIS No. 3), and then cast into thin films by pouring the solutions onto poly(methyl methacrylate) plates and gradually evaporating the solvent at room temperature. The films thus formed were neutralized by dipping in ammonia water, leached in running water, and then dried on the poly(methyl methacrylate) plates at room temperature. The collagen films were quite transparent in the air-dried state, but some of them become turbid, as indicated in Table I, when swollen in saline.

The MC-I preparation was a mixture of mechanically disintegrated natural collagen fibers with an enzymatic solubilized collagen, RC-I, of fractional ratio of 70/30. The mechanically disintegrated natural collagen fibers were dispersed in the acidic aqueous solution of RC-I and then cast into thin films by pouring the suspension on to the poly(methyl methacrylate) plate. MC-II and MC-III were somewhat denatured specimens prepared from film specimens of RC-I, i.e., the film specimen of RC-I, pre-crosslinked by either chemical or photo-
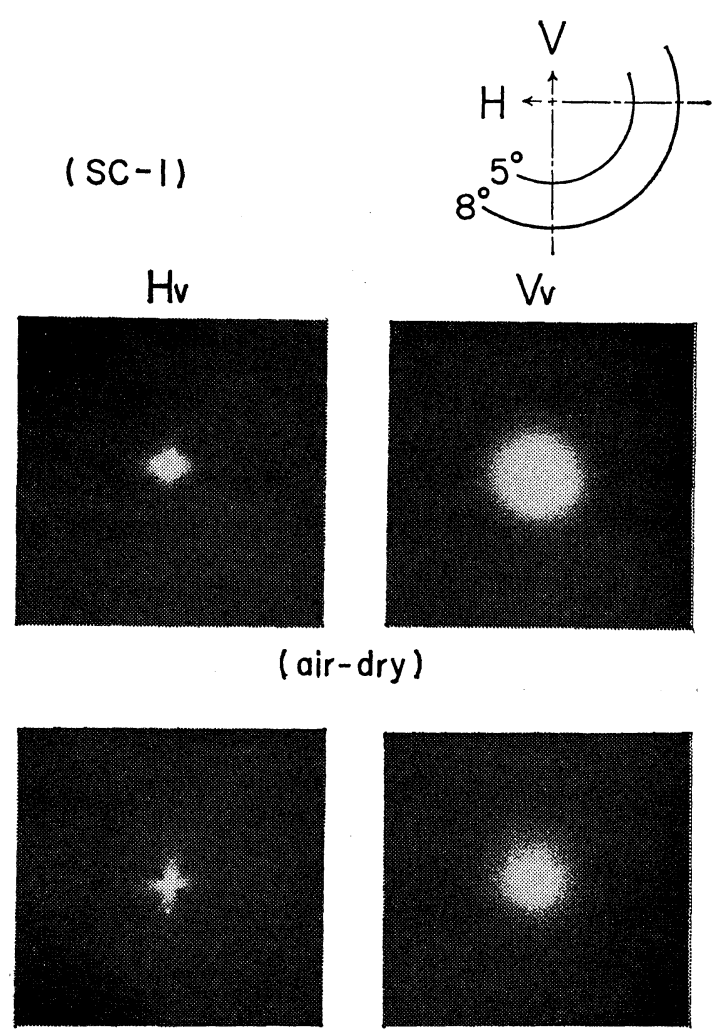

\section{( swollen in saline)}

Figure 1. $H_{v}$ and $V_{v}$ scattering patterns from film specimen cast from an acid soluble collagen, in air-dried state and swollen state in saline. 
chemical methods (glutaraldehyde treatment or irradiation by ultraviolet rays in a swollen state) were dipped in hot-water baths of 85 and $55^{\circ} \mathrm{C}$ for $10 \mathrm{~min}$, respectively. In contrast to the MC-II and MC-III specimens, which were denatured in a swollen but crosslinked state, the MC-IV specimen was denatured in an RC-I acidic aqueous solution at $45^{\circ} \mathrm{C}$, filtered by the sintered glass filter, and cast into thin film by pouring the solution on to the poly(methyl methacrylate) plate as previously explained.

A photographic light-scattering apparatus, which was described in the previous paper, ${ }^{7}$ was used in this experiment. A film specimen and a photographic plate were placed normal to the incident beam, provided by a $\mathrm{He}-\mathrm{Ne}$ gas laser, Model NAL-705Z (Nippon Kagaku Kogyo
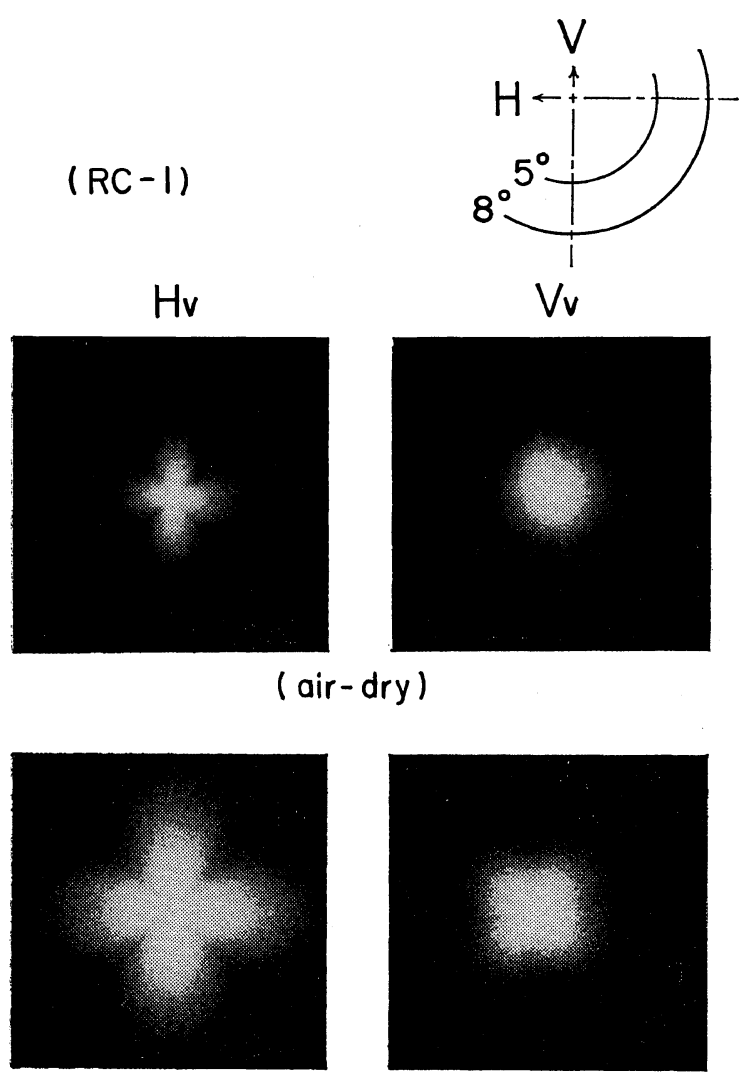

\section{( swollen in saline)}

Figure 2. $H_{v}$ and $V_{v}$ scattering patterns from film specimen cast from an enzymatic solubilized collagen, in air-dried and swollen state in saline.
Inc.). The incident beam was well-collimated and polarized in any direction in a plane perpendicular to the incident beam by using a polarization rotator, Model 310 (Spectra Physics Inc.), and monochromatized to have a wave length of $6328 \AA$. An analyzer was placed between the film specimen and the photographic plate, whose polarization direction was also rotatable in a plane perpendicular to the incident beam. Thus any combination of polarized scatterings, such as $V_{v}$ (vertical polarizer, vertical analyzer) and $H_{v}$ (vertical polarizer, horizontal analyzes) polarizations where the stretching direction of the specimen, if any, is designated vertical, could be obtained.

In all specimens (with the exception of the RC-III) the $H_{v}$ scattering was usually very weak in intensity compared with the $V_{v}$ scattering.
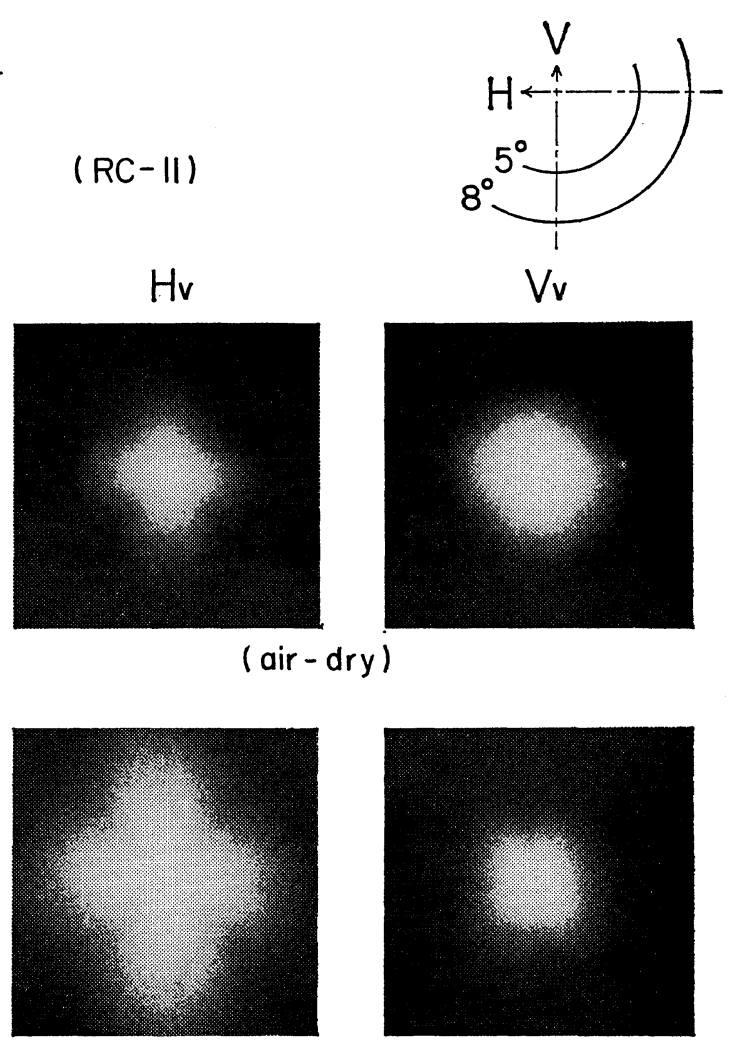

\section{( swollen in saline)}

Figure 3. $H_{v}$ and $V_{v}$ scattering patterns from film specimen cast from an enzymatic solubilized collagen, in air-dried and swollen state in saline. 
Consequently the exposure time for taking the $H_{v}$ scattering pictures was made 60 times longer than that for the $V_{v}$ scattering picture. On the other hand, the $H_{v}$ scattering from the RC-III was unexpectedly strong, and the exposure time given for its $H_{v}$ scattering picture was the same as that for the $V_{v}$ scattering picture.

As may be seen in Figures $1-5$, the polarized light-scattering patterns from the SC-I, RC-I, and RC-II specimens are essentially the same, giving +-type patterns (where the intensity maxima are at 0 and $90^{\circ}$ to the polarizer direction) for the $H_{v}$ scattering in either the air-dried or swollen state in saline, and diffused circular and $\times$-type patterns (where the intensity maxima are at $\pm 45^{\circ}$ to the polarizer direction) for the $V_{v}$ scattering in the air-dried state and the swollenstate, ${ }^{*}$ respectively. The patterns from the RC-

\section{$(\mathrm{RC}-\mathrm{III})$}

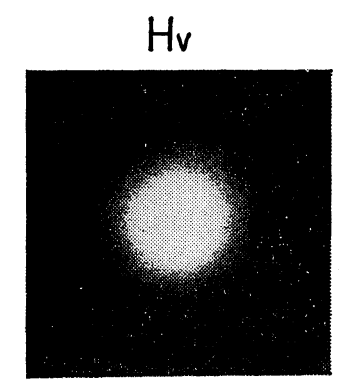

\section{(air-dry)}
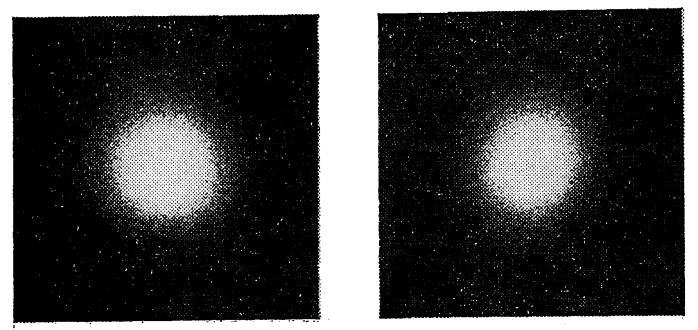

\section{( swollen in saline)}

Figure 4. $H_{v}$ and $V_{v}$ scattering patterns from film specimen cast from an enzymatic solubilized collagen, in air-dried and swollen state in saline.
III and RC-IV specimens are quite different from the above three specimens, giving almost circular patterns for both $H_{v}$ and $V_{v}$ scattering in the air-dried and swollen states.

The + - and $\times$-type patterns, which are observed in the $H_{v}$ and $V_{v}$ scattering from the SC-I, RC-I, and RC-II, especially in the swollen state, ${ }^{*}$ are quite characteristic and differ from the $\times$ and +-type patterns for $H_{v}$ and $V_{v}$ scattering from film specimens of poly- $\alpha$-olefins having spherulitic crystalline superstructure. In addition, the intensity distribution of, for example, the +-type $H_{v}$ pattern characteristically decreases monotonously with increases in the scattering.
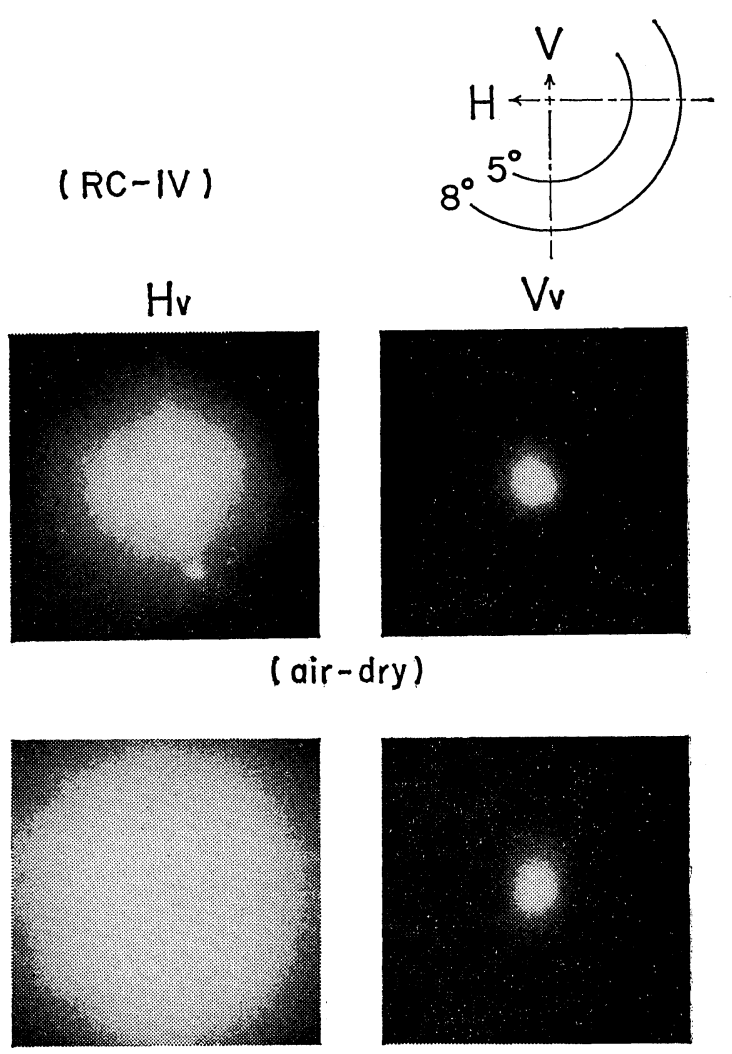

\section{( swollen in saline)}

Figure 5. $H_{v}$ and $V_{v}$ scattering patterns from film specimen cast from an enzymatic solubilized collagen, in air-dried and swollen state in saline.

* The $V_{v}$ scattering pattern from SC-I in the swollen state gives a circular pattern, in contrast to the $\times$-type pattern from RC-I and RC-II. 


\section{Modified Collagens}
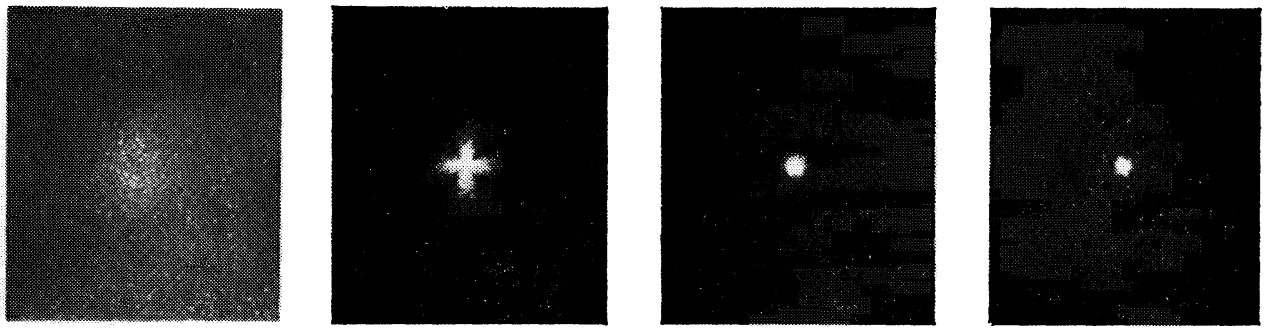

Hv

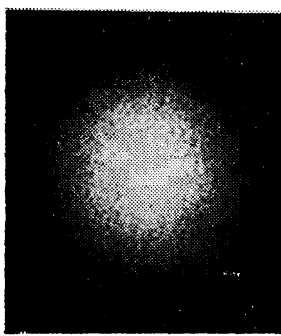

MC-I

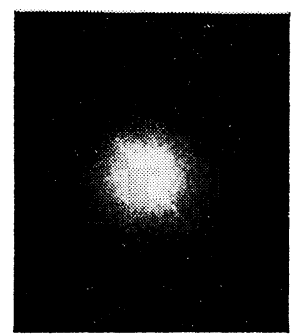

MC-II

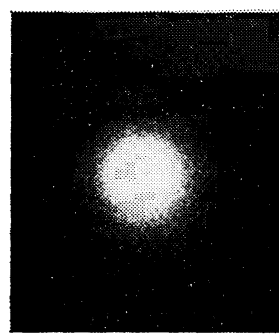

MC-III
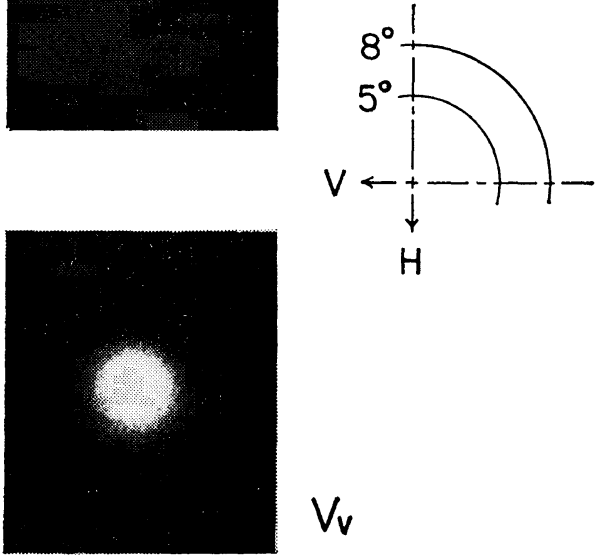

$V_{v}$

MC-IV

Figure 6. $H_{v}$ and $V_{v}$ scattering patterns from several kinds of modified collagens from RC-I, mixed with mechanically disintegrated natural collagen fibers (MC-I), or denatured under varying conditions (MC-II through MC-IV), in an air-dried state.

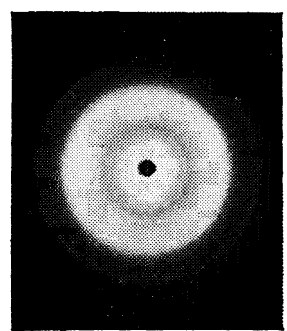

SC-1

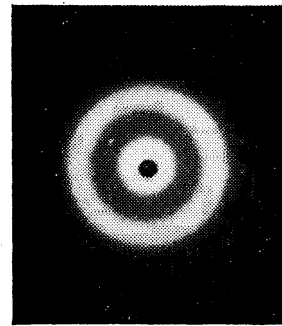

$M C-1$

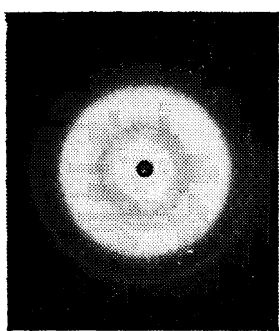

RC-I

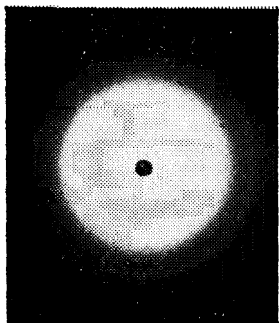

MC- II

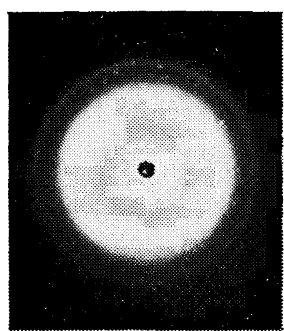

RC-II

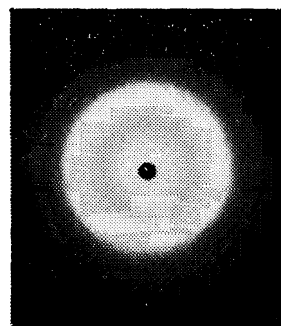

MC-III

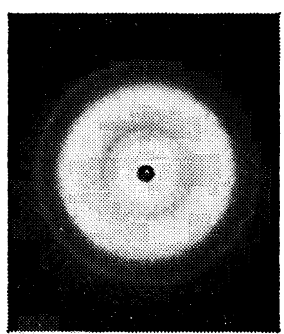

RC- III

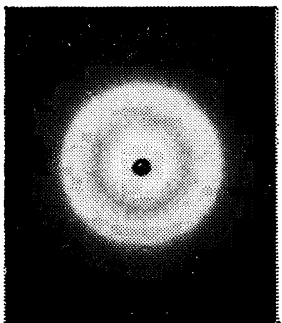

MC-IV

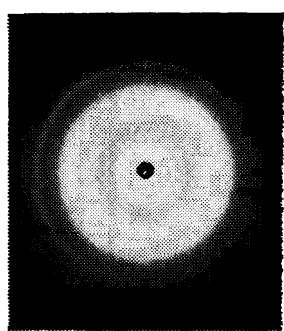

RC-IV

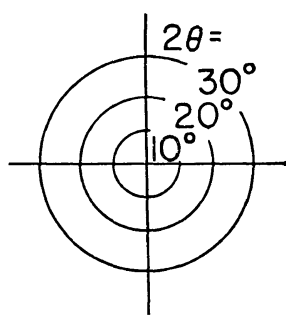

Figure 7. Wide angle X-ray diffraction patterns from collagen films and their denatured films. 
angle, in contrast to the $H_{v}$ pattern from the spherulitic-film specimens having maximum intensity at a particular scattering angle. These characteristics of the scattering pattern may be explained in terms of a crystalline superstructure of these collagen films as a random assembly of anisotropic rods, in contrast to the spherulitic crystalline texture of poly- $\alpha$-olefin films.

By comparing the scattering patterns from the five types of collagen films with the turbid behavior in the swollen state in saline, it may be concluded that the less diffuse and more concentrated the $H_{v}$ pattern is at small scattering angles (as in the case of the SC-I, RC-I, and RC-III specimens) the more turbid the film specimens become. In other words, the more ordered and longer the anisotropic rod is, the more turbid are the specimens in the swollen state.

With regard to the modified collagen films from RC-I, i.e., MC-I, -II, -III, and -IV, the scattering patterns, especially for the +-type $H_{v}$ pattern of the original specimen RC-I, diminish, as illustrated in Figure 6 with exception of MC-I, with the progress of the modification to gelatin by heat-denaturation. On the other hand, the X-ray diffraction patterns of these specimens are hardly changed from those of the original specimens, as illustrated in Figure 7, showing quite sharp Debye-Scherrer rings at almost the same Bragg angles as those of the original specimen. These observations suggest that the light scattering arises mostly from the correlation of the density fluctuations rather than that of orientation fluctuations of local anisotropy. It is therefore suggested that denaturation causes a disintegration of crystalline superstructure rather than of the crystallites themselves, which are too small in orientation correlation distance to give $H_{v}$ scattering at angles smaller than $10^{\circ}$.

Although the $H_{v}$ scattering from the MC-I specimen is too weak to distinguish whether the pattern is circular or not, it is suggested that mixing specimen RC-I with a great amount of mechanically disintegrated natural collagen fibers results in minor reorganization of superstructure of either specimen of RC-I or the natural collagen fiber. That the +-type $H_{v}$ scattering from the MC-II specimen is concentrated within small scattering angles when compared with that from the RC-I specimen, also suggests the growth of superstructure with the modification by glutaraldehyde.

\section{CALCULATIONS}

Figure 8 shows a schematic diagram of the coordinate system of light scattering from an anisotropic rod, whose axis of vector $r$ is oriented with a polar angle $\alpha$ and an azimuthal angle $\beta$, both with respect to the Cartesian coordinates O-xyz. The coordinates are fixed within the film specimen so that the $\mathrm{O} x$-axis having its own unit vector $\boldsymbol{i}$ is taken as the film normal, and the $\mathrm{O} y$ - and $\mathrm{O} z$-axes, whose respective unit vector are $\boldsymbol{j}$ and $\boldsymbol{k}$, are parallel to the film surface. The incident beam having unit vector $\boldsymbol{s}_{0}$ propagates along the $O x$-axis, i.e., $s_{0}=i$, and its polarization direction, whose unit vector is $\boldsymbol{e}$, is taken as parallel to the $\mathrm{O} z$-axis to give $\boldsymbol{e}=\boldsymbol{k}$.

A unit vector $\boldsymbol{s}^{\prime}$ along the scattered ray can be given by

$$
\boldsymbol{s}^{\prime}=\cos \theta \boldsymbol{i}+\sin \theta \sin \mu \boldsymbol{j}+\sin \theta \cos \mu \boldsymbol{k}
$$

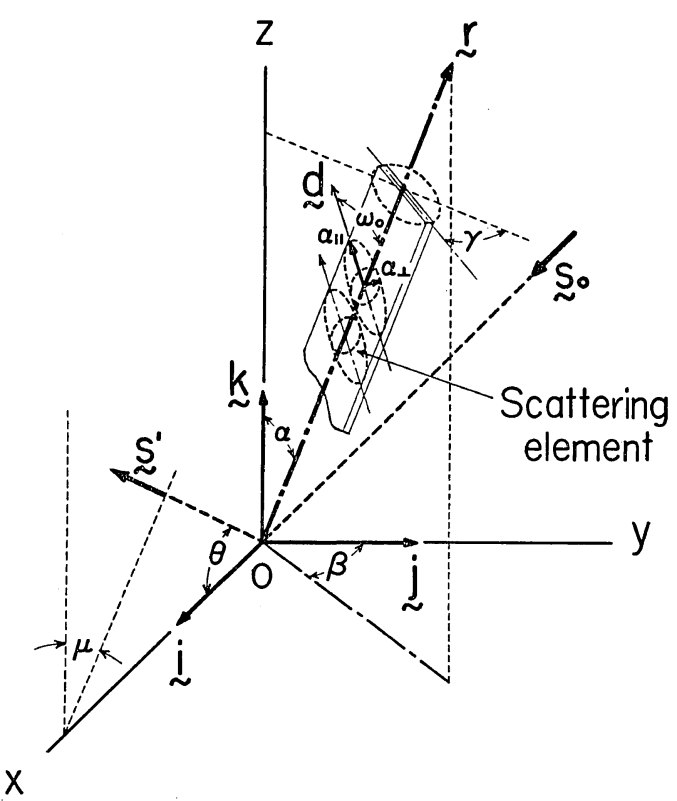

Figure 8. Schematic diagram showing optical and coordinate systems of light scattering from the three-dimensional assembly model of anisotropic rods. 


\section{Light Scattering from Collagen Films}

where $\theta$ and $\mu$ are scattering and azimuthal angles of the scattered ray with respect to the $\mathrm{O} x$ - and $\mathrm{O} z$-axes, respectively. The scattering vector $\boldsymbol{s}$, defined by $\boldsymbol{s}=\left(\boldsymbol{s}_{0}-\boldsymbol{s}^{\prime}\right)$, is given by

$$
\begin{aligned}
\boldsymbol{s}= & \left(\boldsymbol{s}_{0}-\boldsymbol{s}^{\prime}\right)=(1-\cos \theta) \boldsymbol{i} \\
& -\sin \theta \sin \mu \boldsymbol{j}-\sin \theta \cos \mu \boldsymbol{k}
\end{aligned}
$$

Assuming the rod to be infinitesimally thin in diameter but of definite length, in which uniaxially polarizable elements having principal polarizabilities of $\alpha_{\|}$and $\alpha_{\perp}$, are oriented sideby-side with a given polar angle $\omega_{0}$ with respect to the rod axis. That is, every unit vector $\boldsymbol{d}$ along the rotational axes of the elements, and consequently the direction of the principal polarizability $\alpha_{\|}$, is laid parallel to each other within the rod with a common polar angle $\omega_{0}$, as illustrated in Figure 8. Denoting the difference between the polarizability along the element axis and the polarizability of the medium in which the rods are embedded, $b_{r}=\left(\alpha_{\|}-\alpha_{s}\right)$ and the difference between the polarizability perpendicular to the element axis from the polarizability of the medium, $b_{t}=\left(\alpha_{\perp}-\alpha_{s}\right)$, then the induced dipole moment due to the radiation of the incident beam may be given by

$$
\boldsymbol{M}=E_{0}\left\{\delta(\boldsymbol{e} \cdot \boldsymbol{d}) \boldsymbol{d}+b_{t} \boldsymbol{e}\right\}
$$

where $E_{0}$ is the amplitude of the incident beam and $\delta=\left(b_{r}-b_{t}\right)$.

The amplitude of the scattered rays from the scattering elements within the rod may be given by

$$
E=K \int_{-L / 2}^{L / 2} \rho_{0} \cdot(\boldsymbol{M} \cdot \boldsymbol{o}) \cos k(\boldsymbol{r} \cdot \boldsymbol{s}) \mathrm{d} \boldsymbol{r}
$$

where $K$ is a constant; $\rho_{0}$ is the distribution density of the scattering elements per unit length of the rod; $\boldsymbol{o}$ is a unit vector along the polarization direction of the analyzer; $L$ is the length of the rod; $k=2 \pi / \lambda^{\prime}$, and $\lambda^{\prime}$ is the wave length of the light within the specimen.

Further, assuming the rods to be oriented randomly within the space of the specimen with a distribution density $N_{0}$ per unit solid angle, i.e., a random distribution of three Eulerian angles, $\beta, \alpha$, and $\gamma$ for the orientation of the rods with respect to the Cartesian coordinates $\mathbf{O}-x y z$, the intensity distribution of the scattered light from the three-dimensional random as- sembly of the rods may be given by

$$
I=\frac{1}{2} \int_{0}^{2 \pi} \int_{0}^{2 \pi} \int_{0}^{\pi} N_{0} E^{2} \sin \alpha \mathrm{d} \alpha \mathrm{d} \beta \mathrm{d} \gamma
$$

From the above equations, the intensity distribution of scattered light under $H_{v}$ and $V_{v}$ polarizations can be obtained by replacing $\boldsymbol{O}$ with $\boldsymbol{j}$ and $\boldsymbol{k}$, respectively, to give the following results

$$
\begin{aligned}
I(\theta, \mu)_{H_{v}} & =K_{1}\left\{\left[105 \sin ^{2} 2 \mu \cos ^{4}(\theta / 2)+12\right.\right. \\
& \left.-60 \cos ^{2}(\theta / 2)\right] \cdot P_{4}\left(\cos \omega_{0}\right) \cdot A(U) \\
& +\left[60 \cos ^{2}(\theta / 2)-40\right] \cdot P_{2}\left(\cos \omega_{0}\right) \cdot B(U) \\
& +28 C(U)\} \\
I(\theta, \mu)_{V_{v}} & =K_{2}\left\{6 P_{4}[\cos \mu \cos (\theta / 2)] \cdot P_{4}\left(\cos \omega_{0}\right)\right. \\
& \times A(U)+(15+35 p) \cdot P_{2}[\cos \mu \cos (\theta / 2)] \\
& \times P_{2}\left(\cos \omega_{0}\right) \cdot B(U)+(7 / 16)(12+40 p \\
& \left.\left.+60 p^{2}\right) \cdot C(U)\right\} \\
& =K_{2}^{\prime}\left[\cos 4 \mu \cos ^{4}(\theta / 2)(1 / 2) \cdot P_{4}\left(\cos \omega_{0}\right)\right. \\
& \times A(U)+(2 / 7) \cos 2 \mu\left\{\left[7 \cos { }^{4}(\theta / 2)\right.\right. \\
& \left.-6 \cos ^{2}(\theta / 2)\right] \cdot P_{4}\left(\cos \omega_{0}\right) \cdot A(U) \\
& \left.+2(3+7 p) \cos ^{2}(\theta / 2) \cdot P_{2}\left(\cos \omega_{0}\right) \cdot B(U)\right\} \\
& +(3 / 70)\left[35 \cos ^{4}(\theta / 2)-40 \cos { }^{2}(\theta / 2)+8\right] \\
& \times P_{4}\left(\cos _{0}\right) \cdot A(U)+(4 / 21)(3+7 p) \\
& \times\left[3 \cos ^{2}(\theta / 2)-2\right] \cdot P_{2}\left(\cos \omega_{0}\right) \cdot B(U) \\
& \left.+(1 / 15)\left(12+40 p+60 p^{2}\right) \cdot C(U)\right] \quad\left(7^{\prime}\right)
\end{aligned}
$$

where $K_{1}, K_{2}$, and $K_{2}^{\prime}$ are constants, $P_{2}$ and $P_{4}$ are the second and fourth order Legendre functions defined by $P_{2}(X)=\left(3 X^{2}-1\right) / 2$ and $P_{4}(X)=$ $(1 / 8)\left(35 X^{4}-30 X^{2}+3\right)$, respectively. $p, A(U), B(U)$, and $C(U)$ are given by

$$
\begin{gathered}
p=\left(a_{\perp}-\alpha_{s}\right) /\left(\alpha_{\|}-\alpha_{\perp}\right)=b_{t} / \delta \\
A(U)=(1 / 8)(35 A-30 B+3 C) \\
B(U)=(1 / 2)(3 B-C) \\
C(U)=C
\end{gathered}
$$

and where

$$
\begin{gathered}
A=\left(1 / U^{5}\right)\left(\frac{U^{3}}{6}-\frac{2 U^{2}-1}{8} \sin 2 U\right. \\
\left.-\frac{U}{4} \cos 2 U\right) \\
B=\left(1 / 2 U^{2}\right)\left(1-\frac{\sin 2 U}{2 U}\right)
\end{gathered}
$$




$$
\begin{gathered}
C=\frac{\operatorname{Si} 2 U}{U}-\frac{1-\cos 2 U}{2 U^{2}} \\
U=\left(2 \pi L / \lambda^{\prime}\right) \sin (\theta / 2)
\end{gathered}
$$

and $\mathrm{Si}$ is the sine-integral.

As can be seen from eq 6, the shape of the $H_{v}$ scattering pattern has, in general, a four-fold symmetry with respect to the azimuthal angle $\mu$. The type of pattern depends on whether the value of $\boldsymbol{P}_{4}\left(\cos \omega_{0}\right)$ is positive, zero, or negative. When the value is positive the pattern must be $\times$-type and is most extended in the contour plot at azimuthal angles given by $(\pi / 4)+n(\pi / 2)$. When the value is zero the pattern is circularly symmetric having no directional dependence on the azimuthal angle. When the value is negative the pattern is +-type and is most extended at azimuthal angles of $n(\pi / 2)$, where $n$ is integer.

The polar angle $\omega_{0}$ which makes the value of $\boldsymbol{P}_{4}\left(\cos \omega_{0}\right)$ zero and makes the $H_{v}$ pattern circularly symmetric, is found as either $30^{\circ} 33^{\prime}$ or $70^{\circ} 07^{\prime}$, which are a little larger than the angles, $22^{\circ} 30^{\prime}$ or $67^{\circ} 30^{\prime}$, found for the two-dimensional random assembly by Stein, et al. ${ }^{14}$ The polar angles ranging between the two critical values, $30^{\circ} 33^{\prime}$ and $70^{\circ} 07^{\prime}$, give the +-type pattern, while polar angles outside this range give the $x$-type pattern.

Figure 9 shows the results of the calculations of $H_{v}$ patterns fixing the polar angle as $0,30,50,55$, 70 , and $90^{\circ}$ to give the $\times$-type, almost circular, +-type, +-type, almost circular, and $\times$-type, respectively. The value of $L / \lambda^{\prime}$ is taken as 40 , and the polar angles of 50 and $55^{\circ}$ are selected to make the value of $\boldsymbol{P}_{4}\left(\cos \omega_{0}\right)$ most negative and the value of $P_{2}\left(\cos \omega_{0}\right)$ zero, respectively. As seen from the figure, the calculated results demonstrate the above changes in patterns with increases in the polar angle. The patterns are a little sharper in azimuthal distribution in comparison to those obtained by Stein, et al., from the two-dimensional model. ${ }^{14}$

On the other hand, the shape of the $V_{v}$ scat-

\section{Hv patterns $\left(L / \lambda^{\prime}=40\right)$}
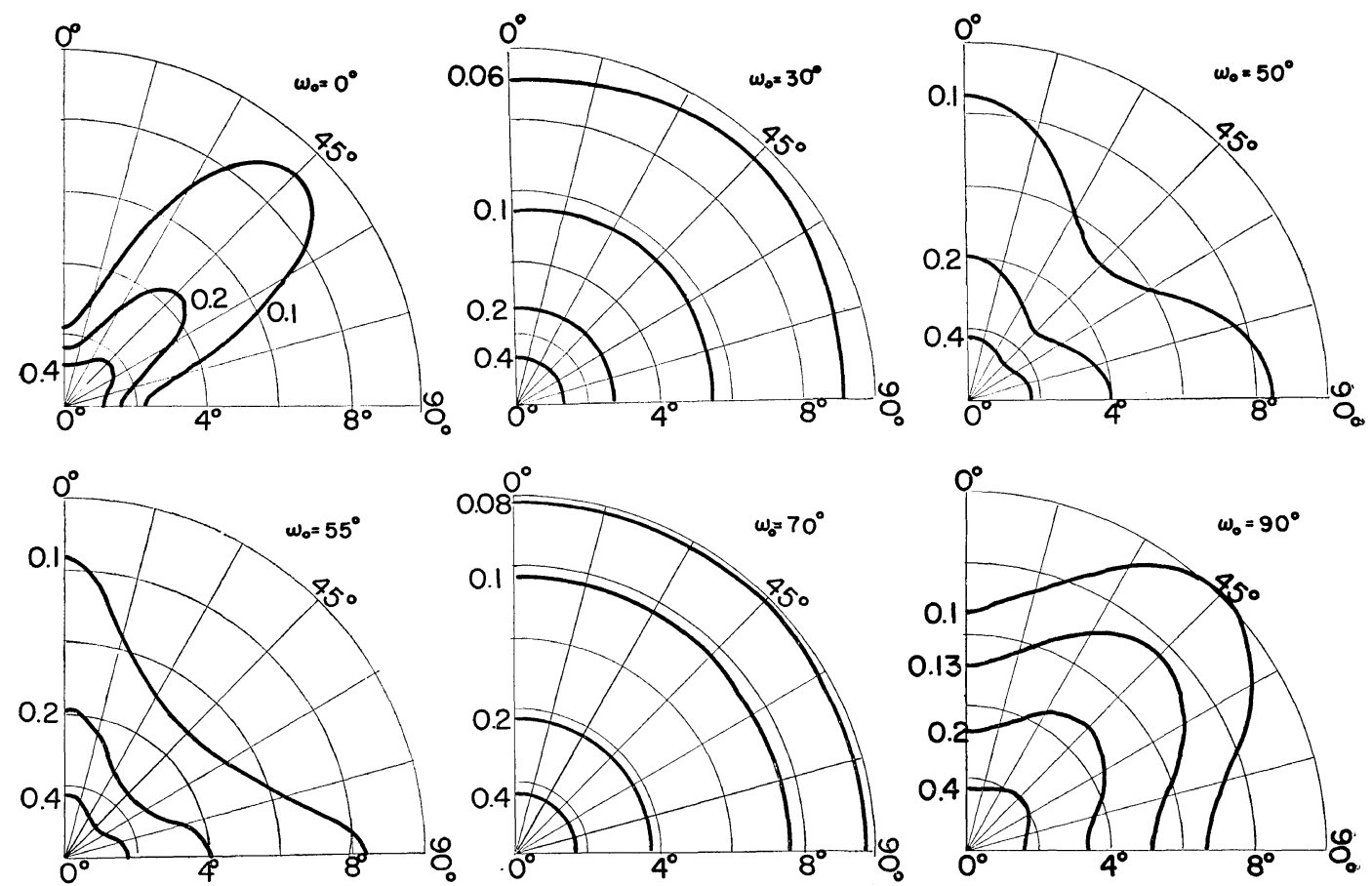

Figure 9. Intensity distribution of $H_{v}$ scattering calculated from eq 6 taking the value of $L / \lambda^{\prime}$ as 40 and varying the polar angle $\omega_{0}$ step-wise by $0,30,50,55,70$, and $90^{\circ}$. 
tering pattern is, as recognized from eq 7 , four-fold, two-fold, or circularly symmetrical with respect to the azimuthal angle, depending on the relative magnitudes of the first, second, and the other terms in the right hand side of eq $7^{\prime}$ to each other. When the first term is relatively large the pattern must be four-fold symmetric; when the second term is predominant the pattern may be two-fold symmetric, and when the other terms, which are independent of the azimuthal angle, are relatively large the pattern must be circularly symmetry.

Figures 10-13 show four series of calculated results of the $V_{v}$ scattering from eq 7, for which the value of $L / \lambda^{\prime}$ is again taken as 40 and the polar angle $\omega_{0}$ is altered to $0,30,50$, 55,70 , and $90^{\circ}$ for given values of $p$, slightly negative, zero, unity, and highly positive, respectively. As may be noted from the figures, when the value of $p$ is slightly negative the change in the scattering pattern with different polar angles is most obvious, changing from a horizontal dumb-bell type to $\times$-type at $\omega_{0}=55^{\circ}$ to a vertical dumb-bell type pattern. When the value of $p$ becomes highly positive the above change is less obvious, giving in all cases an almost circular pattern. That is, when the value of $p$ is slightly negative, the contribution from terms other than the first and second in the right hand side of eq $7^{\prime}$ to the $V_{v}$ scattering is small, which results in the above change in the scattering pattern from two-fold symmetry to four-fold symmetry to two-fold symmetry again due to the alternating changes of the contributions from the first and second terms with increases in the polar angle $\omega_{0}$.

As may also be noted from eq 6 , the intensity distribution of the $H_{v}$ scattering along the azimuthal angle, results only from the first term in the righthand side of the equation. When one takes the scattering angles as being sufficiently small to approximate $\cos (\theta / 2)=1$, the difference

\section{$V_{V}$ patterns $\left(p=-0.27, L / \lambda^{\prime}=40\right)$}
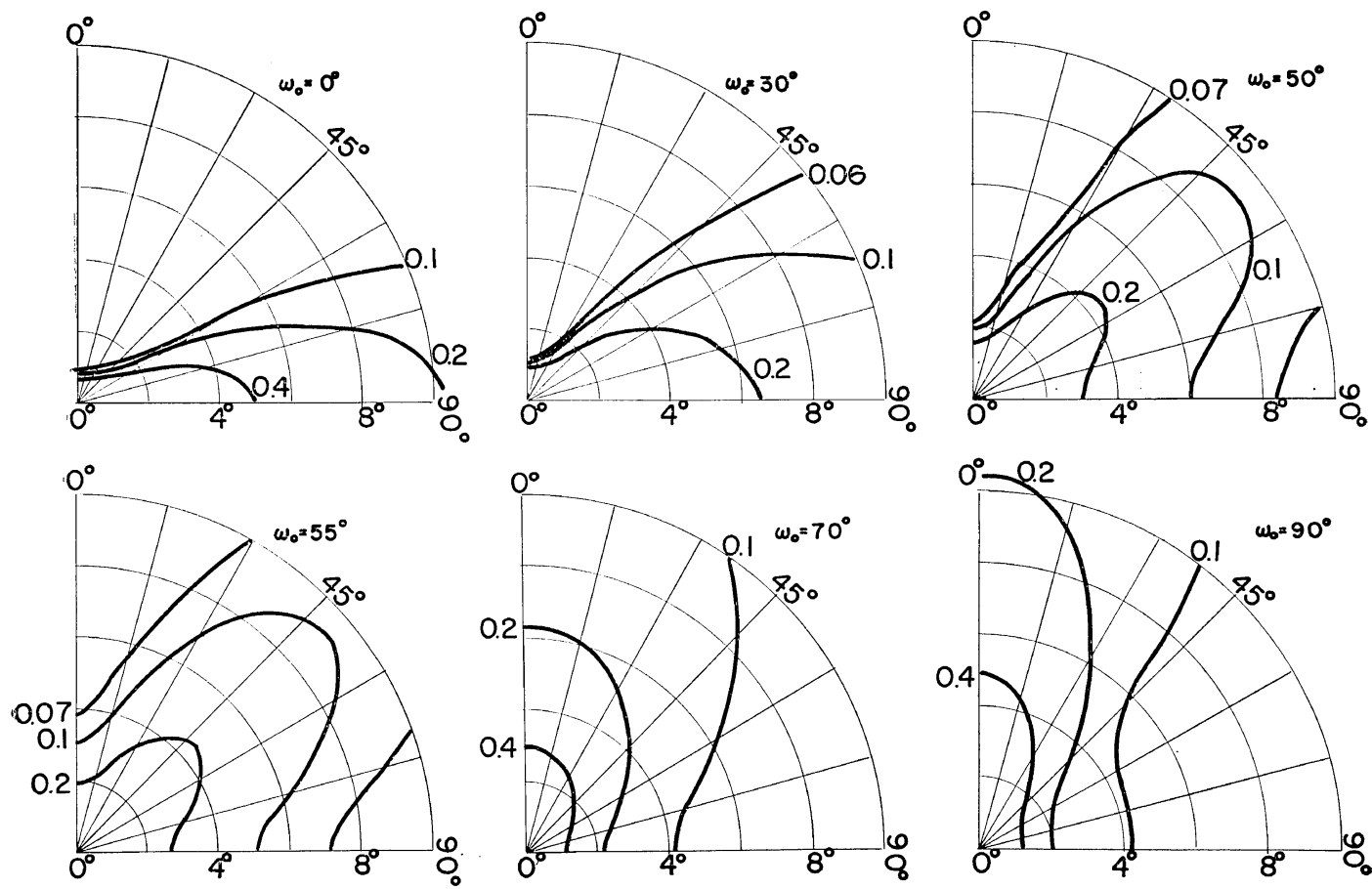

Figure 10, Intensity distribution of $V_{v}$ scattering calculated from eq 7 taking the value of $L / \lambda^{\prime}$ as 40 , fixing the value of $p$ as -0.27 , and varying the polar angle $\omega_{0}$ step-wise by 0 , $30,50,55,70$, and $90^{\circ}$. 
between the scattering intensities at $\mu=0^{\circ}$ and $\mu=45^{\circ}$ may be given in terms of the first term as follows

$$
\begin{aligned}
\left(I_{H_{v}}\right)_{\mu=45^{\circ}}- & \left(I_{H_{v}}\right)_{\mu=0^{\circ}} \\
= & K_{3}\left(35 \cos ^{4} \omega_{0}-30 \cos ^{2} \omega_{0}+3\right) \\
& \times(35 A-30 B+3 C)
\end{aligned}
$$

where $K_{3}$ is a constant.

For a given polar angle $\omega_{0}$ the difference is a function of $U$ only and must reach a maximum at a particular value of $U$, i.e., $U_{\max }=4.80$. Therefore the ascertainment experimentally of the scattering angle $\theta_{\max }$, at which the difference is maximized, makes it possible to evaluate the length of the rod, $L$, from the following relation

$$
U_{\max }=4.80=\left(2 \pi L / \lambda^{\prime}\right) \sin \left(\theta_{\max } / 2\right)
$$

provided that the difference is accurately observed at sufficiently small scattering angles without any disturbance from the direct beam passing through the specimen.

In contrast, the experimental finding of $\theta_{\max }$, if possible, makes the determination of the polar angle $\omega_{0}$ possible from the ratio of $\left(I_{H_{v}}\right)_{\mu=0^{\circ}}$ $/\left(I_{H_{v}}\right)_{\mu=45^{\circ}}$, which is given by

$$
\begin{aligned}
\left(I_{H_{v}}\right)_{\mu}=0^{\circ} /\left(I_{H_{v}}\right)_{\mu=45^{\circ}} & f\left(U, \omega_{0}\right) \\
& =\frac{f\left(U, \omega_{0}\right)+2 P_{4}\left(\cos \omega_{0}\right)(35 A-30 B+3 C)}{f(U)}
\end{aligned}
$$

where

$$
\begin{aligned}
f\left(U, \omega_{0}\right)= & -4 \cos ^{4} \omega_{0}(35 A-30 B+3 C) \\
& +8 \cos ^{2} \omega_{0}(15 A-12 B+C) \\
& -4(3 A-2 B-C)
\end{aligned}
$$

The ratio of $\left(I_{H_{v}}\right)_{\mu=0^{\circ}} /\left(I_{H_{v}}\right)_{\mu=45^{\circ}}$ at $\theta_{\max }$ must be a function of $U_{\max }$ and $\omega_{0}$, from which $\omega_{0}$ can be determined.

\section{$V_{V}$ patterns $\left(p=0, L / \lambda^{\prime}=40\right)$}
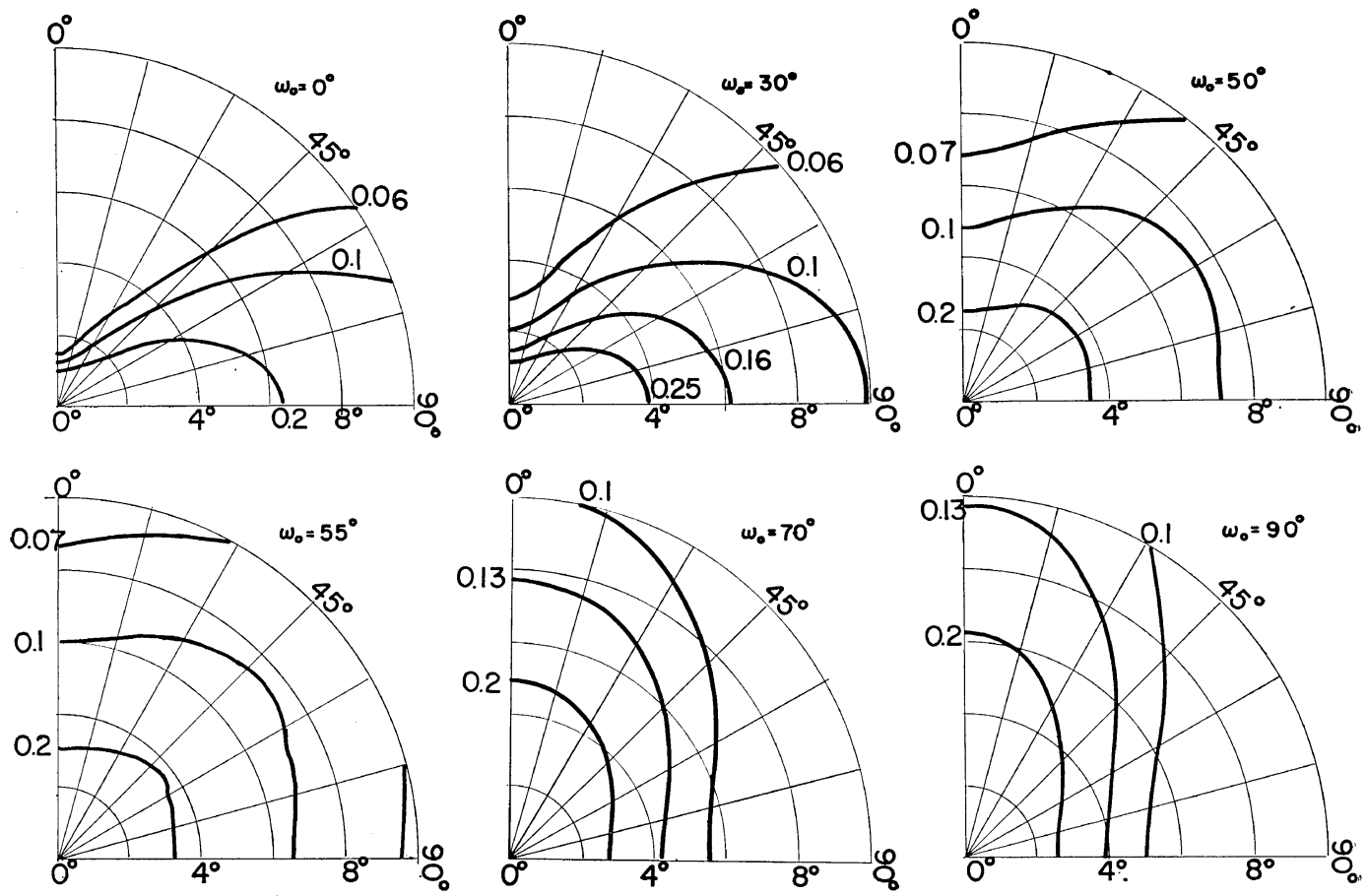

Figure 11. Intensity distribution of $V_{v}$ scattering calculated from eq 7 taking the value of $L / \lambda^{\prime}$ as 40 , fixing the value of $p$ as zero, and varying the polar angle $\omega_{0}$ step-wise by 0 , $30,50,55,70$, and $90^{\circ}$. 


\section{$V_{V}$ patterns $\left(p=1.0, L / \lambda^{\prime}=40\right)$}
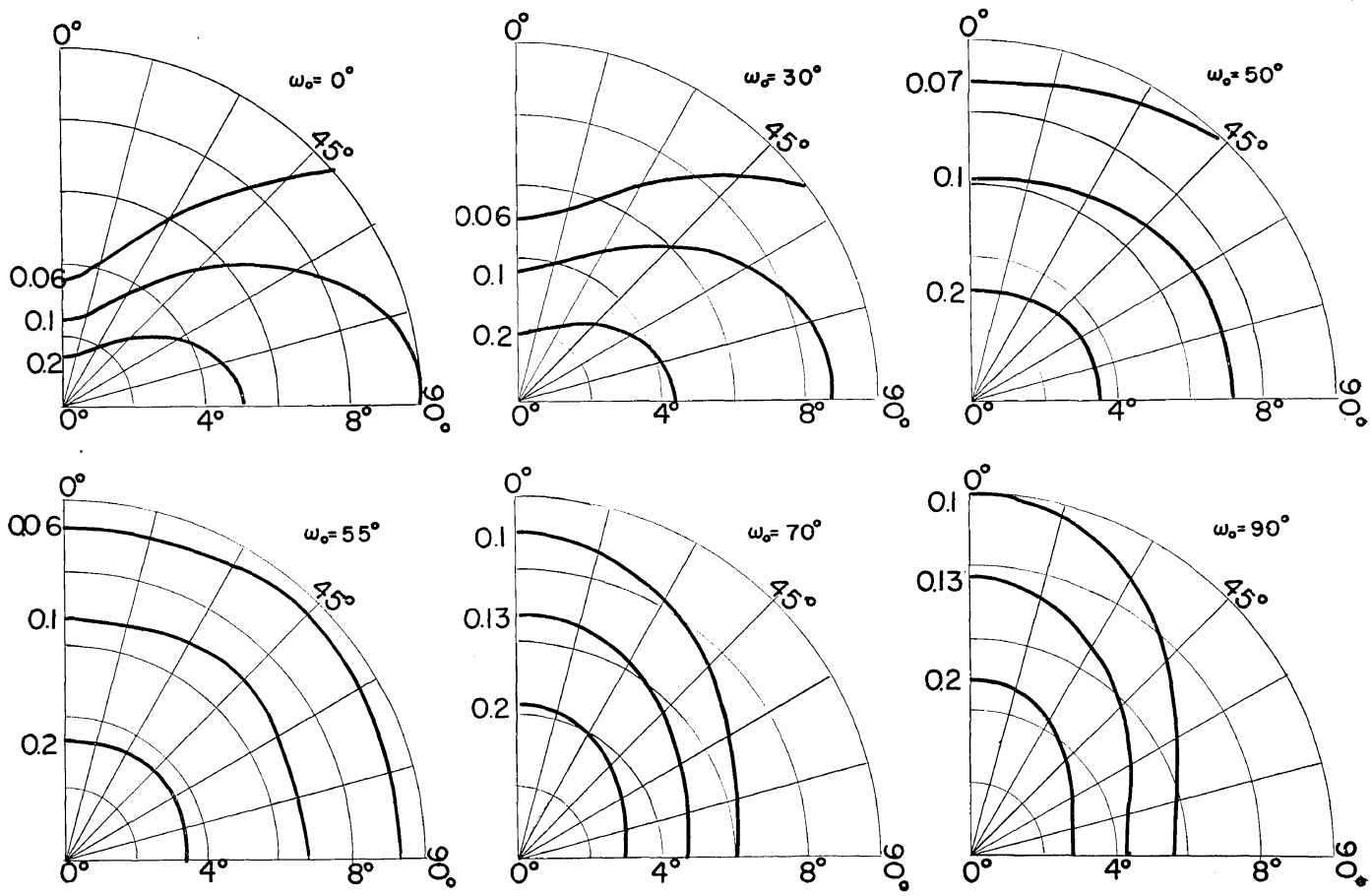

Figure 12. Intensity distribution of $V_{v}$ scattering calculated from eq 7 taking the value of $L / \lambda^{\prime}$ as 40 , fixing the value of $p$ as unity, and varying the polar angle $\omega_{0}$ step-wise by 0 , $30,50,55,70$, and $70^{\circ}$.

\section{DISCUSSION}

As described above, the experimental determination of the polar angle $\omega_{0}$ as well as the length of the anisotropic rod $L$ from the intensity distribution of the $H_{v}$ scattering at two different azimuthal angles, $\mu=0^{\circ}$ and $\mu=45^{\circ}$, within a range of very small scattering angles, is difficult to achieve from an experimental point of view. One can only estimate both magnitudes qualitatively from the scattering patterns themselves.

As illustrated in Figures 1 through 5 , the $H_{v}$ scattering patterns from the collagen films are classified as circular or +-type patterns either in the air-dried or the swollen state, which suggests that the polar angle $\omega_{0}$ must lie in the range, as shown in Figure 9, from around $30^{\circ}$ to around $70^{\circ}$. On the other hand, the $V_{v}$ scattering patterns are classified as circular patterns in the air-dried state, and $\times$-type patterns, or circular or slightly vertical dumb-bell type patterns, in the swollen state. This suggests that the polar angle $\omega_{0}$ must be in the range, as may be seen from Figures $10-13$, from 50 to $70^{\circ}$, providing that the value of $p$ is changed from highly positive to slightly positive, or even to negative with swelling in saline.

If such is the cose, the combination of the above suggestions leads to the conclusions that the polar angle must be around $50^{\circ}$ for samples SC-I, RC-I, and RC-II which give the +-type $H_{v}$ pattern and circular $V_{v}$ patterns in the air-dried state, and the +-type $H_{v}$ pattern and circular or $\times$-type $V_{v}$ patterns in the swollen state. The polar angle must be around $70^{\circ}$ for samples, RC-III and RC-IV which give circular $H_{v}$ and $V_{v}$ patterns in the air-dried state, and circular $H_{v}$ and circular or slightly vertical dumb-bell type $V_{v}$ patterns in the swollen state. The value of $p$ may be quite positive for each sample in the air-dried state, still positive for samples 


\section{Vv patterns $\left(p=10.0, L / \lambda^{\prime}=40\right)$}
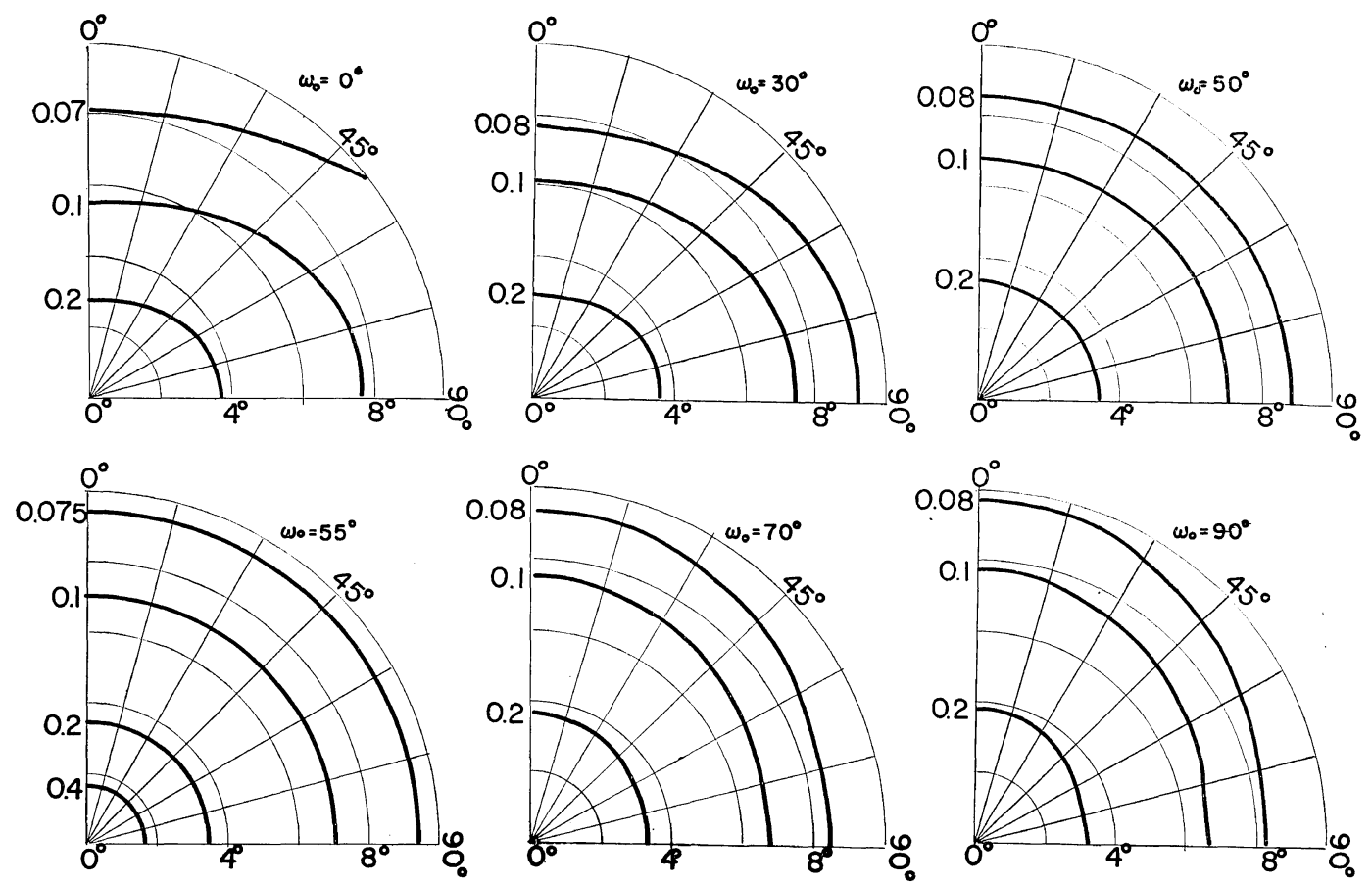

Figure 13. Intensity distribution of $V_{v}$ scattering calculated from eq 7 taking value of $L / \lambda^{\prime}$ as 40 , fixing the value of $p$ as 10 , and varying the polar angle $\omega_{0}$ step-wise by $0,30,50$, 55,70 , and $90^{\circ}$.

SC-I, RC-III, and RC-IV in the swollen state, and almost zero or slightly negative for RC-I and RC-II in the swollen state.

According to eq 8 , the decrease in the value of $p$ with swelling, as postulated above, must arise from the increase in the value of $\alpha_{s}$ with swelling, on the basis of constancy of the values of $\alpha_{\|}$and $\alpha_{\perp}$ with swelling. This is rather difficult to understand in the usual sense of two-phase structures of semicrystalline polymers for which the density of the noncrystalline matrix is usually lower than that of the crystalline region and is further lowered by swelling. The above anomalies may be correlated with the facts that the density of dried collagen in bulk fluctuates significantly over such wide ranges as 1.28 to $2.00(\mathrm{~g} / \mathrm{cc})$ depending on the drying conditions, ${ }^{17}$ that the specific volume of collagen, even in dilute solutions in acetic acid $(\mathrm{pH}, 3.6)$, ranges from 0.700 to 0.580 depending on the kinds of salts added, ${ }^{18}$ and, furthermore, that the density determined from crystal lattice dimensions-found to be $1.33(\mathrm{~g} / \mathrm{cc})$-is often much smaller than the above values for bulk density. ${ }^{19}$

For a more detailed discussion, the assumption of constancy of $\alpha_{\|}$and $\alpha_{\perp}$ with swelling on the basis of the two-phase hypothesis, must be reconsidered by taking into account the structures of collagen not only at the molecular level but also the super-molecular level. The structure at the molecular level has been extensively studied by many authors, as reviewed by Ramachandran ${ }^{19}$ and Veis, ${ }^{20}$ to explain the so-called protofibril in terms of molecular organization. On the other hand, however, details of super-molecular structures involved in the build-up of protofibrils to form the fibrils and ultimately the collagen fibers, are still not clear. This makes it very difficult to identify the scattering elements and the anisotropic rods in terms of definite types of structural units, and 


\section{Light Scattering from Collagen Films}

to explain the large values of polar angles ranging to 50 or 70 , in terms of either optical anisotropy of the collagen molecule itself or the diagonal arrangement of protofibrils or fibrils with the rod axis.

The rod assembly model proposed here, is, of course, a rather crude model of very limited orientation to the scattering elements within rods which are infinitesimally thin in diameter. As one of the generalizations of the rod assembly model, van Aartsen has recently formulated the concept of polarized light scattering from the three-dimensional random assembly of circular as well as lozenge rods being definite in size. ${ }^{21}$ Unfortunately the orientation of scattering elements within the rod was limited to the case where the principal optical axes of the elements were parallel to the rod axis. Further generalizations, taking into account the orientation distribution of scattering elements within the rod, can only be made after more research has been conducted.

Acknowledgements. The authors are indebted to Prof. R. S. Stein, Polymer Research Institute, University of Massachusetts, Amherst, Mass., U.S.A. and Dr. J. J. van Aartsen, AKZO Research and Engineering N. V., Holland, both of whom gave valuable advice and comments on this paper, and the Research Laboratory, Japan Leather Co. Ltd., where the test samples were prepared.

Part of this work was supported by a grant from Scientific Research Funds (Kagaku Kenkyu-hi, 19214-1967) provided by the Ministry of Education, Japan.

\section{REFERENCES}

1. R. S. Stein and M. B. Rhodes, J. Appl. Phys., 31, 1873 (1960).

2. R. S. Stein and P. R. Wilson, J. Appl. Phys.,
33, 1914 (1962).

3. R. S. Stein, P. R. Wilson, and S. N. Stidham, J. Appl. Phys., 34, 46 (1963).

4. S. Clough, J. J. van Aartsen, and R. S. Stein, J. Appl. Phys., 36, 3073 (1965).

5. R. Yang and R.S. Stein, J. Polym. Sci., Part $A-2,7,939$ (1967).

6. R. J. Samuels, J. Polym. Sci., Part A, 3, 1741 (1965); ibid., Part C, 13, 37 (1966); ibid., Part A-2, 6, 1101 (1968).

7. M. Motegi, T. Oda, M. Moritani, and H. Kawai, Polymer J., 1, 209 (1970).

8. C. Picot, R. S. Stein, M. Motegi, and H. Kawai, J. Polym. Sci., Part A-2, in press.

9. R. S. Stein and C. Picot, J. Polym. Sci., Part $A-2$, in press.

10. M. B. Rhodes and R. S. Stein, J. Polym. Sci., Part B, 1, 663 (1963).

11. G. C. Adams and R. S. Stein, J. Polym. Sci., Part A-2, 6, 31 (1968).

12. J. Borch and R. H. Marchessault, J. Polym. Sci., Part C, 28, 153 (1969).

13. P. Horn, H. Benoit, and G. Oster, J. Chem. Phys., 48, 530 (1950)

14. R. S. Stein, P. Erhardt, J. J. van Aartsen, S. Clough, and M. B. Rhodes, J. Polym. Sci., Part C, 13, 1 (1966).

15. P. Doty and T. Nishihara, "Recent Advances in Gelatin Glue Research," Stanby Ed., Pergamon Press, New York, N.Y., 1958, p 92.

16. U.S. Patent-3034852, May 15, 1962, "Solubilization of Insoluble Collagen Fibers and Reconstitution Thereof".

17. E. Heidemann and W. Rietz, Z. Phys. Chem., 334, 224 (1963).

18. Y. Uematsu and M. Muramatsu, Rep. Prog. Polym. Phys. Japan, 8, 531 (1967).

19. G. N. Ramachandran, "Chemistry of Collagen", Ramachandran Ed., Academic Press, New York, N.Y., 1967, p 103.

20. A. Veis, "Macromolecular Chemistry of Gelatin", Academic Press, New York, N.Y., 1964, p 10.

21. J. J. van Aartsen, Eur., Polym. J., 6, 1095 (1970). 